\title{
DISCHARGE MECHANISM IN VOIDS AT SUB-ATMOSPHERIC PRESSURES
}

\author{
B.Ramachandra R.S.Nema \\ Department of High Voltage Engineering \\ Indian Institute of Science \\ Bangalore - 560012 \\ India
}

\begin{abstract}
The physical processes occurring during partial discharges (PD) in voids in solid dielectrics are complicated due to the lack of knowledge of void shape, location and gas pressure. Fast oscilloscopic techniques are needed to measure the build up and decay of current as a function of time for single discharges. The purpose of the present work is to investigate the mechanism of the discharge in artificial voids in thin polypropylene (PP) films at different sub-atmospheric pressures. Efforts have been made in this work to distinguish Townsend-like and streamer-like discharges on the basis of the discharge pulses recorded in terms of rise time, pulse width and peak current for the various void dimensions and pressures studied.
\end{abstract}

\section{Introduction}

$P D$ in voids in solid dielectrics have deleterious effects on the electrical performance of the insulation as they are the sources of discharges taking place at low voltages. The dielectric strength of the void depends on the kind of gas in the void, the gas pressure and the dimensions of the void. PP film is being widely used as dielectric in high voltage insulation. One of the prime cause of insulation degradation is PD in voids created between two adjacent films. Moreover, there is a probability that these voids may be at different sub-atmospheric pressures due to the process of vacuum impregnation. The purpose of the present work is to investigate the possibility of the discharge mechanism inside the void for various void parameters.

The charge carrier motion between electrodes induces current in the electrode leads. However, the rapid changes of the discharge, as may occur in the early phases of breakdown in PD, may or may not show up in the external current since when a discharge is to be studied by means of current measurement, a clear correlation between the current measurements and the internal events is needed [1]. The time resolution of these measurements is limited by the bandwidth with which the current can be monitored. In order to preserve the shape of the discharge pulse and relate it to the physics of the discharge process a time-resolved detection system is needed [2]. In the present work two distinct types of discharges are identified, named large rise time (RT) pulse and sharp rise time pulse, and mechanism responsible for their development has been proposed.

\section{Experimental Setup}

The experimental selup for PD measurements is shown in Figure 1. The sub-divided electrode arrangement is same as that used before [3]. The radius of the measuring electrode should be small to reduce stray capacitances but not too small since otherwise the moving charge carriers also induce a current in the ground connection of the surrounding ring, thus reducing the current through the measuring resistor. The diameter of sub-divided electrode was $2 \mathrm{~cm}$ and $6 \mathrm{~cm}$ for measuring disk and guard electrode respectively with 0.1 $\mathrm{cm}$ annular gap spacing between them. The value chosen for the measuring resistor was $25 \Omega$ formed by two terminating $50 \Omega$ resistors at either end of a $50 \Omega$ co-axial transmission line (RG 214 cable) of one metre length and was fed to a 1 GHz Tektronix TDS 684A digital storage oscilloscope.

Electrical grade biaxially oriented $20 \mu \mathrm{m}$ thick and $11 \mathrm{~cm}$ diameter PP films have been used with an artificial cylindrical void of $0.2 \mathrm{~cm}$ (finite void) and $2.2 \mathrm{~cm}$ (infinite void, considering $2 \mathrm{~cm}$ diameter of the measuring electrode and $0.1 \mathrm{~cm}$ annular gap between measuring disk and guard electrode) diameter made at the centre as shown in Figure 2. Four to ten films are used depending on the void depth (i.e., 80 to $200 \mu \mathrm{m}$ ) required for the middle stack of films while the top and bottom electrodes are pasted with one plane film each using petroleum jelly. Proper care is taken to see that no air bubble exists either between the films or between the film and electrode. The middle stack of films of required void depth is so placed over the bottom electrode, so as to have sufficient gap between the stack and the pasted film of the top electrode. The single stage rotary pump connected to the chamber is used to create the required void pressure inside the chamber. Few minutes are allowed for the required pressure to stabilise inside the chamber. Afterwards, the micrometer head of the Wilson seal arrangement is adjusted to place the sample tightly between the two electrodes. Now the void pressure is the same as the chamber pressure. The experiments were carried oul at inception voltage and room temperature at void pressures of 100,200 and 400 torr. 


\section{Experimental Results}

The current pulse produced by an avalanche and measured as a voltage drop across the measuring resistor is composed of the fast electron component followed by the slow ion drift component. The characterisation of PD pulses is done on the basis of the rise time, pulse width and peak current of the recorded oscillograms. The rise time measured in this work corresponds to $10 \%$ to $90 \%$ of the peak amplitude. The pulse width measured at $50 \%$ of the pulse height is approximately equal to the fall time of the discharge pulse. PD current pulse magnitude is calculated from the peak current of the measured voltage waveform across the $25 \Omega$ resistance.

The variations of the rise time, fall time and peak current of the PD pulses are shown in Tables 1,2 and 3 respectively for the various void dimensions and pressures studied. The experimental values quoted are the average of five measurements. In the present work, two distinct types of discharge pulses are seen each with its own characteristic features. The large rise time pulses are attributed to Townsend-like discharge pulses which are characterised by large transit time of electrons and ions with a small peak value of current, while the sharp rise time pulses are characterised as streamer-like discharge pulses which have short transit times and large peak values. It is to be noted that both large and sharp rise time pulses are observed for 2 $\mathrm{mm}$ void diameter at 100 and 200 torr void pressures for the various void depths studied. However at 400 torr, while for $80 \mu \mathrm{m}$ void depth both Townsend-like and streamer-like pulses are observed but for 120 and $200 \mu \mathrm{m}$ void depths only sharp rise time pulses (streamer-like) are observed.In the case of infinite void diameter, pulses of both types are observed for the various void depths and pressures studied. Typical PD pulses are shown in Figure 3.

\section{Discussion and Conclusion}

It is generally accepted that breakdown in short gaps with metallic electrodes is governed by the Townsend mechanism. Since the most common range of physical void diameters ranges roughly from about 0.1 to $3.0 \mathrm{~mm}$, one would expect the above mechanism to apply for the various void inclusions in the insulation systems. However, because of the highly distorted electric field configuration in voids having dielectric boundaries, there is every possibility that breakdown process is determined by the streamer mechanism [4]. The discharge mechanism will however depend on the gas pressure.

Whatever be the breakdown mechanism, it involves substantial ionisation within the void and the resulting charges tend to distribute so as to oppose the applied field within the void. Thus the resultant field within the void will drop substantially, almost to zero. The charge flow in the circuit due to the drop in the field within the void, produces the PD signal. The next discharge takes place if voltage further rises or at the zero phase of the a.c. voltage or if the charges are cleared and the voltage again increases. In all such cases discharges occur when the voltage equals the inception voltage and the process is repetitive. The overall difference in the pulse shapes of the two discharge mechanisms results primarily from the fact that in the Townsend discharge maximum number of ions and electrons are created near the anode, so that the slow moving ions have to traverse the entire gap in moving to the cathode. Whereas in the streamer discharge, both the ions and electrons are produced throughout the gap and hence ion movement to cathode is fast.

Devins [5] has shown that streamer-like discharges have larger discharge magnitudes than Townsend-like discharges and the pulse width is proportional to the void height for Townsend-like discharges. Further it is shown that the pulse width closely corresponds to the positive ion transit time. Morshuis [2] has shown that Townsend-like discharge pulse is characterised by its width of about 60 ns while streamerlike discharges are characterised by short transit times of about 390 ps. The optical method used also reveals that Townsend-like discharge covers a large area of the void surface. Fromm and Kreuger [6] have shown that the Townsend-like discharge has a small peak value with large pulse width (about $55 \mathrm{ns)} \mathrm{while} \mathrm{streamer-like} \mathrm{discharge} \mathrm{has}$ a large peak value and short pulse width.

In the present work, for infinite void diameter at subatmospheric pressures, the pulse width is found to vary from $74.94 \mathrm{~ns}$ to $322.41 \mathrm{~ns}$ and 8.32 to $33.18 \mathrm{~ns}$ for large and sharp rise time pulses respectively. It is also observed that the pulse peak current for large rise time pulses is much lower compared to sharp rise time pulses. Hence large rise time pulses are characterised as Townsend-like discharges whereas sharp rise time pulses are characterised as streamerlike discharges. This characterisation agrees well with the observations of others $[2,5,6]$. The behavior of the discharge mechanism for $2 \mathrm{~mm}$ void diameter at 100 and 200 torr void pressures is found to be similar to that of the infinite void diameter. But at 400 torr, Townsend-like discharge is not observed for 120 and $200 \mu \mathrm{m}$ void depths while both discharge mechanisms are observed for $80 \mu \mathrm{m}$ void depth. It can be concluded from the observations made that there exists a critical void parameter (diameter to depth ratio) and pressure at which there is a transition from Townsend to streamer discharge mechanism. 


\section{References}

(1) J.M.Wetzer. C.Wen and P.C.T.van der Laan, "Bandwidth Limitations of Gap Current Measurements", IEEE Intl. Symp. on Elec. Insul., Boston, pp. 355-358, 1988.

[2] P.H.F.Morshius. "Time Resolved Discharge Measurements", IEE Intl. Conf, on Partial Discharges, pp. 43-46, 1993.

[3] B.Ramachandra and R.S.Nema, "Characterisation of Partial Discharges Pulses in Artificial Voids in Polypropylenc Films used in Capacitors", IEEE Intl. Symp. on Elec. Insul., Monirreal. pp $517-520,1996$

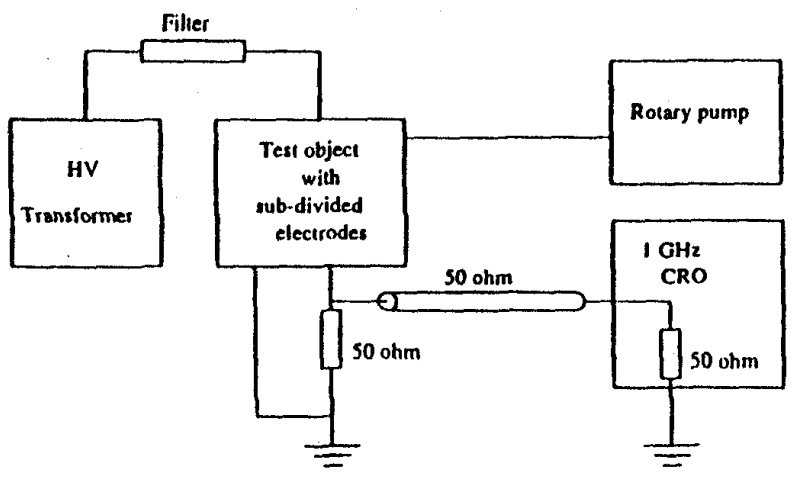

Figure 1 Experimental setup for PD measurements

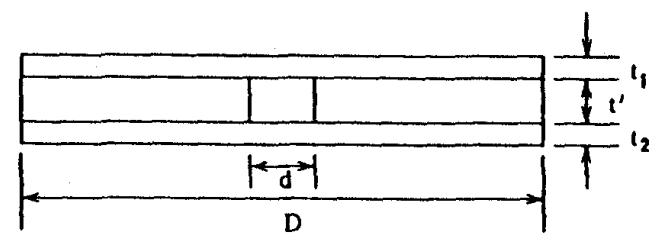

Figure 2 Sample

$t_{1}=t_{2}=$ thickness of the top and bottom fitms $=20 \mu \mathrm{m}$

$t^{\prime}=$ thickness of the films containing the void

$d$ = diameter of the void

$\mathrm{D}=$ overall diamcter of the sample
14) R.Bartnikas and E.J.McMahon, Engineering Dielectrics. Vol.I. Corona Measurement and Interpresation. American Society for Testing Materials. Philadelphia, 1979.

(5) J.C.Devins, "The Physics of Partial Discharges in Solid Dielectrics", IEEE Trans. Elec. Insul. Vol. 19. pp. 475-495. 1984.

[6] U.Fromm and F.H.Kreuger, "Statistical Behaviour of Internal Partial Discharges at d.c. Voltage", Japanese j. Appl. Phys., Vol. 33, pp. 6708-6715, 1994.
Tablo 1 Variation of rise time

\begin{tabular}{|c|c|c|c|c|c|c|c|c|c|}
\hline \multirow{2}{*}{\multicolumn{2}{|c|}{$\begin{array}{l}\text { Tressurel } \\
\text { Vuisd l)epull, }\end{array}$}} & \multicolumn{4}{|c|}{ Targe IrT Tulsea (ng) } & \multicolumn{4}{|c|}{ Sliarp ITt Pulses (ns) } \\
\hline & & \multicolumn{2}{|c|}{ Positive Pulse } & \multicolumn{2}{|c|}{ Negalive Pulse } & \multicolumn{2}{|c|}{ Posilive Pulsc } & \multicolumn{2}{|c|}{ Negalive Pulse } \\
\hline & & $\begin{array}{c}2 m 111 \\
\text { Dia }\end{array}$ & Tin? & $\begin{array}{c}2 m m \\
\text { Dia }\end{array}$ & $\begin{array}{l}\text { Tnt } \\
\text { Dia }\end{array}$ & $\begin{array}{c}2 \mathrm{~min} \\
\mathrm{Dia}\end{array}$ & $\begin{array}{l}\text { In } \\
\text { Din }\end{array}$ & $\begin{array}{c}2 \mathrm{~min} \\
\mathrm{Dia}\end{array}$ & $\begin{array}{l}\text { IIIT } \\
\text { Dia }\end{array}$ \\
\hline \multirow{3}{*}{$\begin{array}{l}100 \\
\text { forr }\end{array}$} & $80 \mathrm{~mm}$ & 33.39 & 136.27 & 3.20 & 124.14 & 8.85 & 8.32 & 8.67 & ij. 83 \\
\hline & $120 \mathrm{~cm}$ & 35.07 & 130.16 & 37.66 & 178.56 & 10.96 & 9.95 & T1.32 & 10.22 \\
\hline & $200 \mathrm{~mm}$ & 35.69 & 117.10 & ग.11 & 100.10 & 10.58 & 11.29 & 10.18 & 13.58 \\
\hline \multirow{3}{*}{$\begin{array}{l}200 \\
\text { lorr }\end{array}$} & $80 \mathrm{~mm}$ & 23.90 & 105.10 & 21.96 & 80.56 & 5.71 & 5.31 & 5.58 & 5.42 \\
\hline & $120 \mathrm{~mm}$ & 21.14 & 77.43 & 17.90 & 77.31 & 6.96 & 3.80 & 6.79 & 4.11 \\
\hline & $200 \mathrm{~km}$ & T9.5i & 62.39 & 13.69 & 68.31 & 6.21 & 2.51 & 6.52 & 3.02 \\
\hline \multirow{3}{*}{$\begin{array}{l}100 \\
\text { torr }\end{array}$} & $80 \mathrm{~cm}$ & 12.11 & 17.12 & 11.63 & 59.38 & 1.11 & 3.93 & 1.11 & 3.28 \\
\hline & $120 \mu m$ & - & 37.78 & $=$ & 38.88 & 2.19 & 2.28 & 2.11 & 2.28 \\
\hline & 2001111 & - & 32.71 & $=$ & 33.56 & 2.11 & 2.19 & 2.13 & 2.18 \\
\hline
\end{tabular}

Table 2 Variation of rall tims

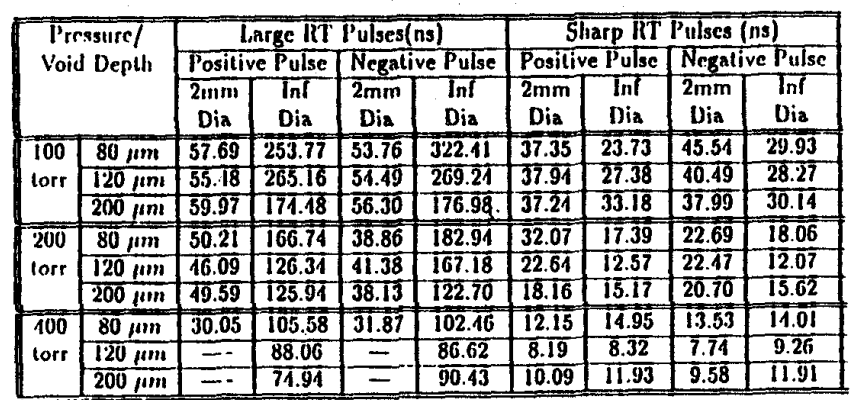

Table 3 Varlation of pulse peak current

\begin{tabular}{|c|c|c|c|c|c|c|c|c|c|}
\hline \multirow{3}{*}{\multicolumn{2}{|c|}{$\begin{array}{l}\text { Prossurr/ } \\
\text { Vuid Deptli }\end{array}$}} & \multicolumn{4}{|c|}{ Targr RT Pulacs (ni $)$} & \multicolumn{4}{|c|}{ Sharp RT Pulses $(\mathrm{m} \Lambda)$} \\
\hline & & \multirow{2}{*}{\multicolumn{2}{|c|}{ Positive Pulse }} & \multirow{2}{*}{\multicolumn{2}{|c|}{ Ncgalive Pulse }} & \multirow{2}{*}{\multicolumn{2}{|c|}{ Positive Pulse }} & \multicolumn{2}{|c|}{ Negalive Pilse } \\
\hline & & & & & & & & & \\
\hline & & $\begin{array}{l}2 m+1 \\
\text { Dia }\end{array}$ & $\begin{array}{l}\text { InI } \\
\text { Dia }\end{array}$ & $\begin{array}{c}2111+11 \\
\text { Dia }\end{array}$ & $\begin{array}{l}\ln 1 \\
\text { Dia }\end{array}$ & $\begin{array}{c}2 \mathrm{~mm} \\
\text { Dia }\end{array}$ & $\begin{array}{l}\text { IIII } \\
\text { Dia }\end{array}$ & $\begin{array}{c}2 m m \\
\text { Dia }\end{array}$ & Dia \\
\hline \multirow{3}{*}{$\begin{array}{l}100 \\
\operatorname{tor} r\end{array}$} & $80 \mathrm{~mm}$ & 2.21 & 1.80 & 2.45 & 1.98 & 6.28 & 3.11 & 7.56 & 7.42 \\
\hline & $120 \mu \mathrm{m}$ & 3.52 & 2.12 & 5.00 & 3.39 & II.44 & 13.37 & 13.02 & 22.18 \\
\hline & $200 \mathrm{~mm}$ & 5.17 & 1.11 & 7.22 & 1.42 & 17.98 & 39.55 & 20.22 & 10.32 \\
\hline \multirow{3}{*}{$\begin{array}{l}200 \\
\text { torr }\end{array}$} & $80,1, n$ & .7 .77 & 3.15 & 4.97 & 3.78 & 20.86 & 16.17 & 2.3 .05 & 78.71 \\
\hline & $120 \mathrm{~mm}$ & 7.98 & 4.77 & 10.00 & $\overline{2} . \overline{93}$ & 20.06 & 33.62 & 27.78 & 36.77 \\
\hline & $206 \mu$ & 8.78 & 2.21 & T2.10 & 2.17 & 38.59 & 18.38 & 37.22 & 13.05 \\
\hline \multirow{3}{*}{$\begin{array}{l}100 \\
\text { torr }\end{array}$} & $80 \mathrm{~mm}$ & 18.0 .5 & 1.18 & 14.75 & 2.82 & 37.73 & 16.27 & 37.02 & 11.75 \\
\hline & $120 \mathrm{~mm}$ & & 3.0 .5 & $=$ & 3.28 & 108.32 & 37.38 & 104.68 & 11.50 \\
\hline & $200 \mathrm{~mm}$ & & 1.05 & $-\infty$ & 4.15 & 115.20 & 12.98 & 110.81 & 13.87 \\
\hline
\end{tabular}



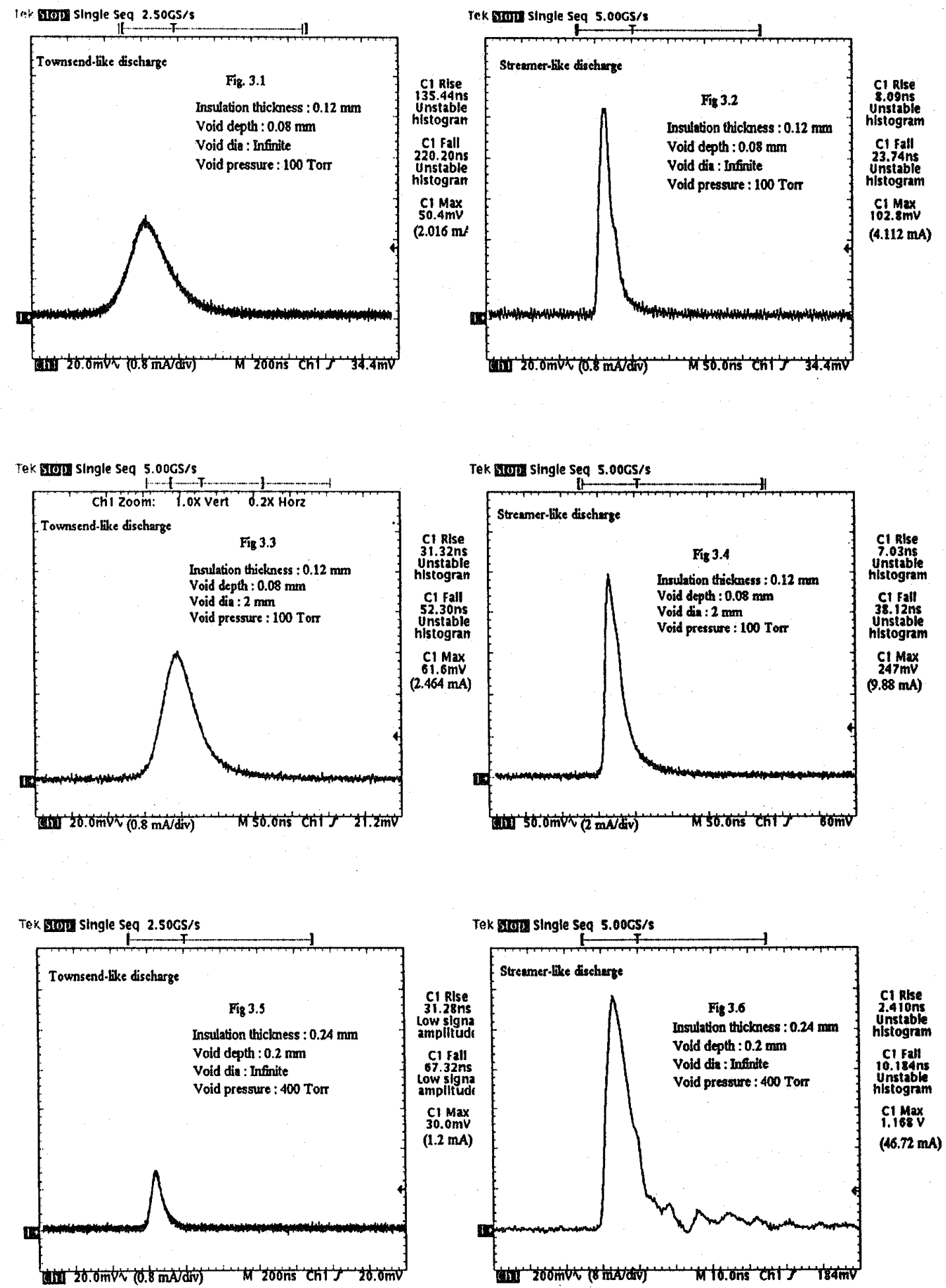

Figure 3 : Typical Partial Discharge Pulses 